\title{
A loop-loop interaction and a K-turn motif located in the lysine aptamer domain are important for the riboswitch gene regulation control
}

\author{
SIMON BLOUIN and DANIEL A. LAFONTAINE \\ Département de Biologie, Faculté des Sciences, Université de Sherbrooke, Sherbrooke, Québec, J1K 2R1, Canada
}

\begin{abstract}
The lysine riboswitch is associated to the lys C gene in Bacillus subtilis, and the binding of lysine modulates the RNA structure to allow the formation of an intrinsic terminator presumably involved in transcription attenuation. The complex secondary structure of the lysine riboswitch aptamer is organized around a five-way junction that undergoes structural changes upon ligand binding. Using single-round transcription assays, we show that a loop-loop interaction is important for lysine-induced termination of transcription. Moreover, upon close inspection of the secondary structure, we find that an unconventional kinkturn motif is present in one of the stems participating in the loop-loop interaction. We show that the K-turn adopts a pronounced kink and that it binds the K-turn-binding protein L7Ae of Archaeoglobus fulgidus in the low nanomolar range. The functional importance of this K-turn motif is revealed from single-round transcription assays, which show its importance for efficient transcription termination. This motif is essential for the loop-loop interaction, and consequently, for lysine binding. Taken together, our results depict for the first time the importance of a K-turn-dependent loop-loop interaction for the transcription regulation of a lysine riboswitch.
\end{abstract}

Keywords: riboswitch; loop-loop interaction; kink-turn; 2-aminopurine fluorescence

\section{INTRODUCTION}

Riboswitches are highly structured genetic control elements that are located in the $5^{\prime}$-untranslated region $\left(5^{\prime}\right.$-UTR) of several messenger RNAs of prokaryotes and also in eukaryotes (Kubodera et al. 2003; Lai 2003; Sudarsan et al. 2003a; Mandal and Breaker 2004). Riboswitches are composed of two modular domains, an aptamer and an expression platform, which, respectively, senses a specific metabolite and controls gene expression. In all cases studied, riboswitches perform their regulation via ligand-dependent structural changes, and because they can operate in vitro in absence of a protein cofactor, it has been proposed that they can regulate gene expression without the assistance of any protein (for review, see Grundy and Henkin 2004; Nudler and Mironov 2004; Winkler 2005), making them potential remnants of ancient gene regulatory systems. A large

Reprint requests to: Daniel A. Lafontaine, Département de Biologie, Faculté des Sciences, Université de Sherbrooke, Sherbrooke, Québec, J1K 2R1, Canada; e-mail: Daniel.Lafontaine@USherbrooke.ca; fax: (819) 821-8049.

Article published online ahead of print. Article and publication date are at http://www.rnajournal.org/cgi/doi/10.1261/rna.560307. number of different riboswitches have been described (for review, see Breaker 2006), and a recent bioinformatics study has provided evidence that additional riboswitches still wait to be discovered, given that numerous additional RNA motifs sharing characteristics with riboswitches were identified (Barrick et al. 2004).

In most bacteria, the amino acid lysine derives from aspartate via the diaminopimelate (DAP) pathway (Patte 1994). This pathway is of special interest for antibacterial drugs given that the absence of DAP in mammalian cells allows for the use of the DAP biosynthetic genes as bacteria-specific drug targets (Hutton et al. 2003). The first two stages of the DAP pathway are common for the biosynthesis of amino acids of the aspartate family, namely, lysine, threonine, and methionine, and are catalyzed by aspartokinase and aspartate semialdehyde dehydrogenase. Bacillus subtilis has three aspartokinases: DAP-inhibited DapG, lysine-inhibited aspartokinase-II LysC, and aspartokinase-III, which are inhibited by simultaneous addition of threonine and lysine and encoded by the $y c l M$ gene. Although most genes of lysine biosynthesis are repressed by lysine, little is currently known about their regulation mechanisms (Patte 1994; Kochhar and Paulus 1996; Patte 
et al. 1998; Mader et al. 2002). Mutations in leader regions of lysC genes Escherichia coli and B. subtilis have been shown to release repression of gene expression by lysine ( $\mathrm{Lu}$ et al. 1992; Patte et al. 1998). Based on the identification of a short transcript corresponding to the B. subtilis lys $C$ leader region, it has been proposed that lysine controls transcription and translation by a mechanism in which no protein factor serves as the genetic regulator (Kochhar and Paulus 1996; Liao and Hseu 1998; Rodionov et al. 2003). Instead, a group of conserved elements was identified upstream of several lysine biosynthesis genes and was shown to be important for lysine-dependent transcription termination in vitro (Grundy et al. 2003; Sudarsan et al. 2003b). Through phylogenetic analyses, this motif was designated as the L box or the LYS element and was found to reside upstream of additional lysine-related genes (Rodionov et al. 2004). The binding of lysine to the lysC RNA leader region was shown to cause structural changes consistent with the hypothesis that lysine binding promotes transcription attenuation by preventing the formation of an antiterminator stem through a riboswitch mechanism (Grundy et al. 2003; Sudarsan et al. 2003b).

The secondary structure of the L box aptamer domain of the B. subtilis lysine riboswitch (Fig. 1) is based on conserved primary sequence elements (Grundy et al. 2003; Rodionov et al. 2003; Sudarsan et al. 2003b). The core of the L box is organized around a fiveway junction exhibiting a 2HS1HS4 HS4HS3 arrangement (using the IUB nomenclature of junctions) (Lilley et al. 1996) and it has been shown by inline probing assays to be reorganized upon lysine binding (Sudarsan et al. 2003b). The binding of lysine stabilizes the P1 stem, which can be considered as an anti-antiterminator, given that its formation prevents the adoption of an antiterminator stem (Grundy et al. 2003; Rodionov et al. 2003; Sudarsan et al. 2003b). Helices P2-P5 are most probably involved in the formation of the correct structure of the aptamer, and a loop E-like motif or an S turn motif has been speculated to reside in the middle region of the P2 helix (Grundy et al. 2003; Sudarsan et al. 2003 b). In addition, covariation analysis has suggested that a loop-loop interaction occurs between the P2 and P3 stem-loops (Fig. 1; Grundy et al. 2003; Rodionov et al. 2003). Similar long-range interactions are found in other riboswitch systems, such as the adenine riboswitch, where we have shown that a loop-loop interaction is very important for ligand binding (Lemay et al. 2006). An additional internal loop in the P2 helix that matches the GA motif found in both the T box and S box leader RNAs (Winkler et al. 2001) has been predicted to correspond to the K-turn motif (Klein et al. 2001), which introduces a severe kink in the RNA backbone (Grundy et al. 2003).

Here, a mutational analysis shows that a loop-loop interaction between the stem-loops P2 and P3 is important for the biological function of the lysine riboswitch. Upon examination of the P2 helical domain, we identify an unconventional kink-turn motif and show its importance for lysine-induced termination of transcription, most probably by allowing formation of the loop-loop interaction. By introducing the fluorescent adenine structural analog 2-aminopurine (2AP) in the core of the aptamer,

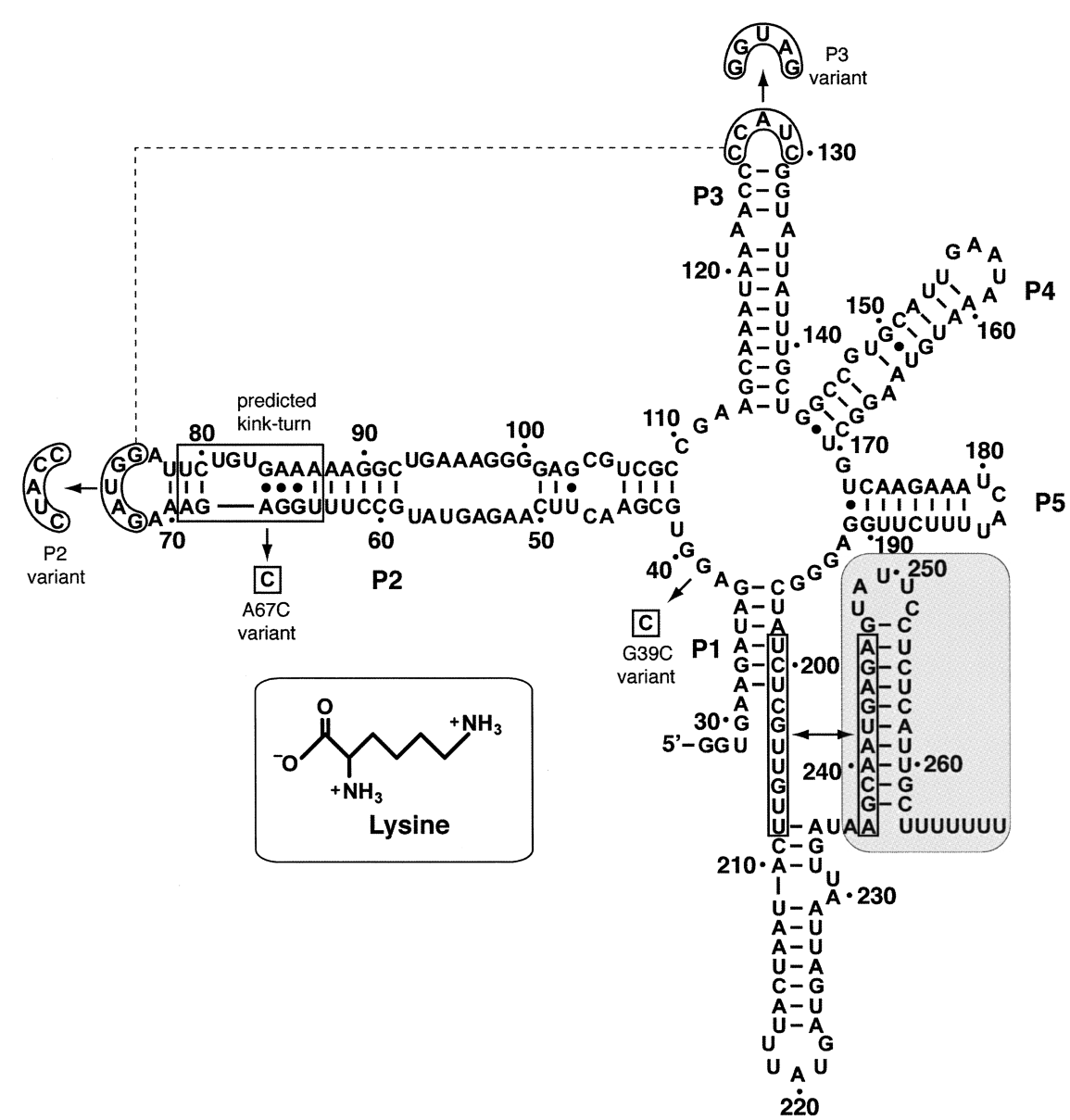

FIGURE 1. Sequence and secondary structure of the lysC lysine riboswitch of Bacillus subtilis (Grundy et al. 2003; Sudarsan et al. 2003a). The represented secondary structure is shown with the transcription terminator structure (shaded region). Regions involved in the formation of the antiterminator helix are boxed and indicated by an arrow. The loop-loop interaction is indicated by a dotted line. The K-turn is shown in the P2 helical domain in a box. The mutations studied in this work are represented by boxed sequences. The chemical structure of lysine is shown in the inset. 
we observe an important change induced by magnesium ions that is dependent upon the correct formation of the loop-loop interaction, indicating that distal structural elements are important for the core folding of the lysine aptamer. Our results provide the first experimental evidence that a loop-loop interaction in the B. subtilis lysine riboswitch has a major role in the riboswitch biological function and strongly suggest that an unconventional Kturn motif is very important for the adoption of the looploop interaction.

\section{RESULTS}

\section{Lysine promotes premature termination of transcription}

We first analyzed transcription attenuation by the lysine riboswitch using single-round in vitro transcription assays. This technique has been previously used to study a variety of riboswitches (Epshtein et al. 2003; McDaniel et al. 2003; Mandal et al. 2004; McDaniel et al. 2005; Sudarsan et al. 2006), and particularly the one responding to lysine (Grundy et al. 2003; Sudarsan et al. 2003b; Blount et al. 2007). A DNA template containing the B. subtilis glyQS promoter upstream of the lysine riboswitch and a 95 nucleotide (nt) sequence downstream of the terminator stem was generated for our studies (Fig. 2A). The conformation of the riboswitch in the absence of ligand should prevent the formation of the terminator stem, allowing the RNA polymerase to transcribe a complete mRNA (readthrough product). However, lysine binding to the aptamer is expected to stabilize the anti-antiterminator P1 stem and to allow the terminator stem to be formed, ultimately leading to premature transcription termination (terminated product).

Single-round in vitro transcription reactions were carried out by using E. coli RNAP in the presence of increasing concentrations of lysine. In the presence of $1 \mu \mathrm{M}$ ligand, low transcription termination is observed with $\sim 25 \%$ of terminated products (Fig. 2B). However, the addition of L-lysine leads to an increase of transcription termination up to a value of $\sim 60 \%$ in the presence of $10 \mathrm{mM}$ lysine (Fig. 2B). The ratio of terminated product (\%T) was calculated for each reaction and plotted as a function of ligand concentration (Fig. 2C). Resulting data were well fitted by a simple two-state model (see Materials and Methods) and the lysine concentration required to obtain half of the change in transcription termination (defined as $\left.\mathrm{T}_{1 / 2}\right)$ is $2.1 \pm 0.2 \mathrm{mM}$. Similar results were observed in a recent study where a value of $\mathrm{T}_{1 / 2} \sim 5 \mathrm{mM}$ was obtained (Blount et al. 2007). Given that $\mathrm{T}_{1 / 2}$ values are highly dependent on experimental protocols, the small difference between our value and the one reported most probably results from variations in transcription conditions (e.g., ribonucleotide concentrations) (S. Blouin and D.A. Lafontaine, pers. observation).

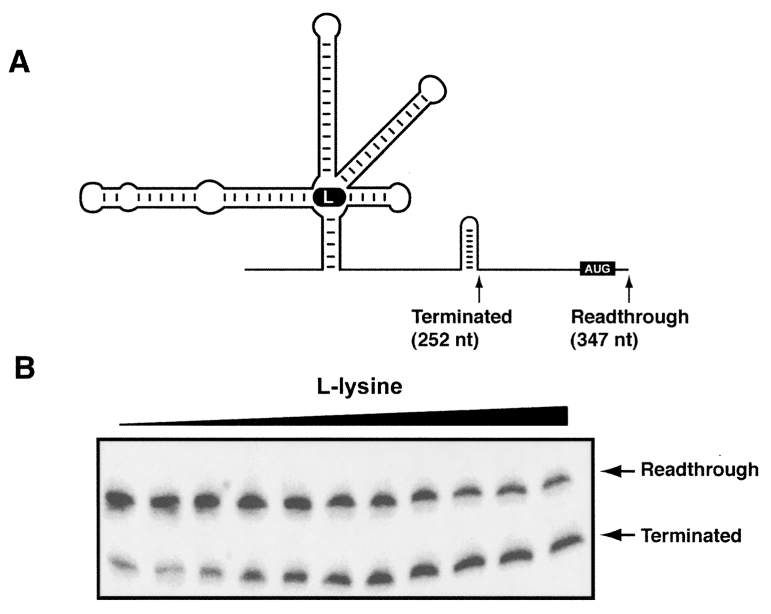

C

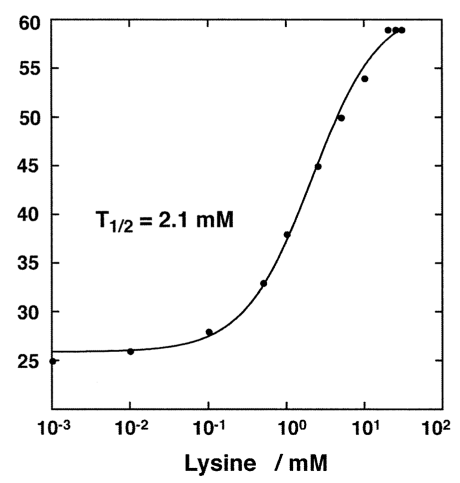

FIGURE 2. Lysine-induced riboswitch transcription termination. $(A)$ Schematic showing constructs used in these experiments. The terminated $(252 \mathrm{nt})$ and readthrough (347 nt) transcription products are indicated by arrows. Lysine is indicated by a rounded rectangle. While the premature termination product is expected to occur in the presence of ligand, transcription readthrough is expected in its absence. (B) Single-round transcriptions performed in the presence of $1 \mu \mathrm{M}, 10 \mu \mathrm{M}, 100 \mu \mathrm{M}, 500 \mu \mathrm{M}, 1 \mathrm{mM}, 2.5 \mathrm{mM}, 5 \mathrm{mM}, 10 \mathrm{mM}$, $20 \mathrm{mM}, 25 \mathrm{mM}$, and $30 \mathrm{mM}$ L-lysine and resolved on 5\% denaturing polyacrylamide gels. Readthrough and terminated products are indicated on the right. $(C)$ Percentage of termination $(\% \mathrm{~T})$ is plotted as a function of lysine concentration. The line shows a two-state model from which a $\mathrm{T}_{1 / 2}$ value $=2.1 \mathrm{mM}$ lysine was calculated.

\section{The loop-loop interaction is important for transcription termination}

It has been previously proposed that a loop-loop interaction takes place between loops P2 and P3 (Fig. 1; Grundy et al. 2003). To determine whether the loop-loop motif is important for ligand binding, single-round in vitro transcriptions were carried out by disrupting the putative interaction (Fig. 3). To assess the relative importance of the loop-loop interaction, a single-point mutation (G39C), which has previously been shown to cause lys $C$ derepression (Vold et al. 1975; Lu et al. 1992; Sudarsan et al. 2003b), was used in our transcription assay as a negative control. As expected, upon introduction of the G39C mutation, the lysine-induced transcription attenuation mechanism was 


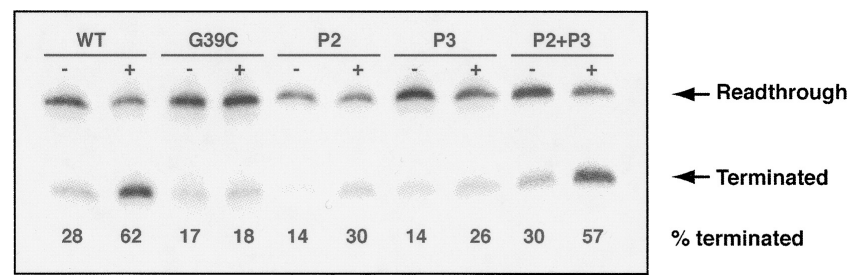

FIGURE 3. A loop-loop interaction is important for transcription termination. Single-round transcriptions were carried out in absence $(-)$ and in presence $(+)$ of $5 \mathrm{mM}$ lysine for each riboswitch variant. Readthrough and terminated products were separated by gel electrophoresis and are indicated on the right. Reactions were performed for the natural sequence (WT), the G39C core variant, P2 and P3 looploop-deficient variants, and for the P2 + P3 variant. The percentage of terminated product for each reaction is indicated below the gel.

severely affected, yielding only $\sim 20 \%$ of termination in the absence and presence of lysine (Fig. 3). Similar results have been previously obtained by Breaker and coworkers (Sudarsan et al. 2003b), indicating the importance of G39 in the riboswitch regulation control.

Two riboswitch variants were made in which each of the P2 or P3 loop nucleotides involved in the proposed looploop interaction was changed for its respective counterpart (P2 and P3 variants, respectively; Fig. 3). In absence of lysine, both riboswitch variants yielded a reduced transcription termination efficiency $(\sim 14 \%)$. Addition of lysine to transcription reactions resulted in termination efficiencies of $\sim 30 \%$ and $\sim 26 \%$ for the P2 and P3 variants, respectively. In contrast to what is observed for the G39C variant, the presence of lysine results in an increase of transcription termination, albeit to a reduced level compared to the natural sequence. However, when both P2 and P3 loop mutations are introduced simultaneously, the lysine-induced transcription termination activity is restored to near the wild-type level (Fig. 3). The observed restoration of the riboswitch activity suggests that the loop-loop interaction is required for efficient transcriptional control and that the interaction takes place provided that base pairing is maintained.

\section{An unconventional K-turn motif is present in the $L$ box domain}

Upon visual inspection of the secondary structure of the B. subtilis lys $C$ aptamer domain, it can be observed that a region of the P2 arm may fold as a K-turn motif (Fig. 1). The K-turn structure is known to introduce a severe bend into the helical axis where it subtends an included angle of $60^{\circ}$ (Klein et al. 2001). This motif is characterized by the presence of two tandem G•A pairs, an asymmetric loop, and a nucleotide completely exposed to the solvent (Klein et al. 2001). The K-turn is organized around a central coaxial base stack that makes an important hydrophobic core for the structure of the motif. The overall structure of the K-turn is highly conserved and occurs in several locations in the 23S rRNA Haloarcula marismortui (Ban et al. 2000) and in the 16S rRNA of Thermus thermophilus (Schluenzen et al. 2000). K-turn motifs are very often bound by protein factors, making them important recognition elements. The $B$. subtilis $l y s C$ and the consensus K-turn motifs shown in Figure 4A indicate that the lys $C$ K-turn sequence does not match the consensus sequence. For instance, the single-stranded sequence of lysC (UGU) does not correspond to the consensus (RNN), and some conserved base pairs also differ. Because of the observed differences, we decided to investigate if the putative lys $C$ K-turn motif adopts a structure similar to conventional K-turn elements.

The highly kinked conformation of the K-turn has previously been studied using gel electrophoresis by Lilley and coworkers, where it was shown that K-turn-containing molecules exhibit severely retarded electrophoretic mobility (Goody et al. 2004). The gel electrophoresis technique is very sensitive to study global conformational changes in nucleic acids (Marini et al. 1982; Diekmann and Wang 1985; Bhattacharyya and Lilley 1989; Hsieh and Griffith 1989; Bhattacharyya et al. 1990; Tang and Draper 1990; Luebke and Tinoco 1996; Lafontaine et al. 2001, 2002a; Goody et al. 2004; Lemay et al. 2006; Lemay and Lafontaine 2007), and provides a simple yet powerful means to analyze the K-turn motif in solution. To analyze the extent of bending, a set of comparison duplexes was constructed by placing a series of oligoadenine bulges in the same sequence context, to generate RNA duplexes having the same length as the K-turn-containing molecules. Such oligoadenine bulges cause axial bending, the magnitude of which depends on the number of unpaired bases in the bulge (Bhattacharyya et al. 1990; Tang and Draper 1990; Gohlke et al. 1994; Lilley 1995; Zacharias and Hagerman 1995; Luebke and Tinoco 1996). The relative mobilities of radioactively labeled RNA species were compared in a native polyacrylamide gel and electrophoresed in the presence of $10 \mathrm{mM}$ magnesium ions. The series of oligoadenine bulged species exhibits the expected progressive reduction of mobility with bulge size, which is known to result from an axial kinking that becomes greater as the number of unpaired bases increases (Fig. 4B; Gohlke et al. 1994; Zacharias and Hagerman 1995). The lysC K-turn species, when introduced in a corresponding RNA duplex, displays a markedly retarded mobility that is similar to an RNA species having a five-adenine bulge (Fig. 4B). This is in agreement with crystal structures of RNA molecules containing conventional K-turn structures (Ban et al. 2000; Schluenzen et al. 2000; Klein et al. 2001) and with a previous gel electrophoresis analysis performed on the Kt-7 K-turn motif, where a highly kinked conformation was deduced (Goody et al. 2004). According to transient electric birefringence (TEB) experiments, an RNA species having a five-adenine bulge displays a bend angle of $\sim 70^{\circ} \pm 3^{\circ}$ in the presence of $2 \mathrm{mM}$ magnesium (Zacharias and 
A
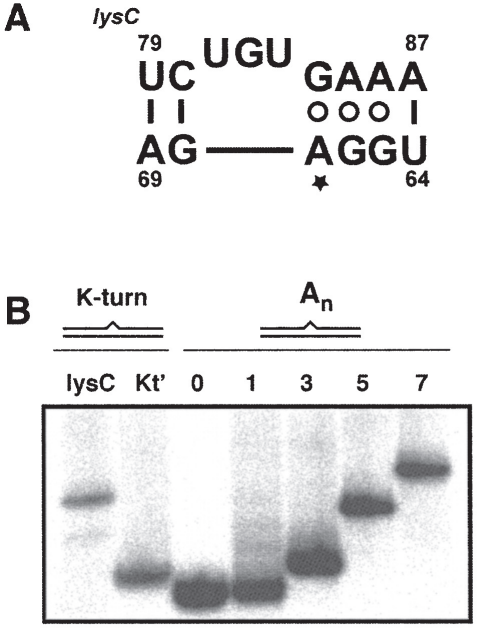

C

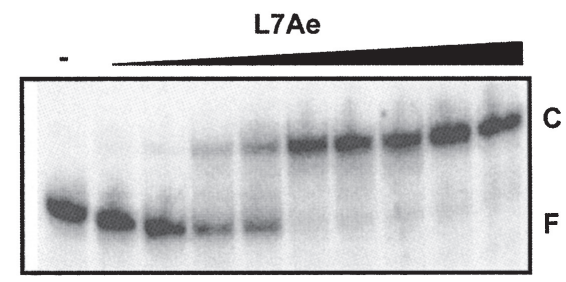

D

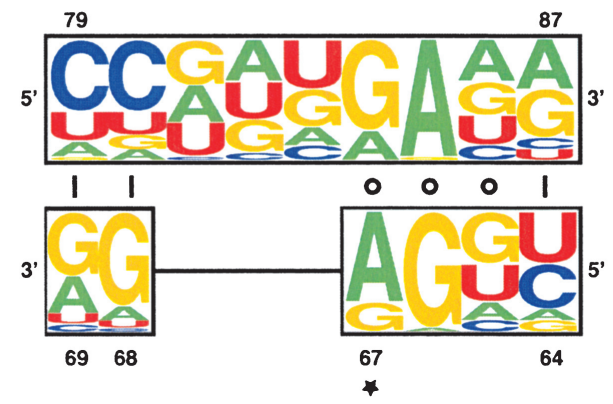

FIGURE 4. A K-turn motif is present in the $y_{s} C$ aptamer. $(A)$ The sequence and predicted secondary structure of $B$. subitlis lys $C$ K-turn motif (left). The secondary structure has been written to match the established K-turn consensus (right) (Klein et al. 2001). Watson-Crick and purine base pairs are shown by vertical lines and circles, respectively. The star shows the nucleotide A67, known to be important for the adoption of the K-turn motif (Goody et al. 2004). $\mathrm{R}$ denotes a purine consensus. (B) Electrophoretic migration of the $l y s C \mathrm{~K}$-turn motif in presence of magnesium ions. Comparison of electrophoretic mobility of RNA duplexes containing a centrally located $l_{y s} C \mathrm{~K}$-turn motif (K-turn) or variants $\left(\mathrm{A}_{\mathrm{n}}\right)$ with duplexes kinked by virtue of a central oligoadenine bulge. Note that the $y_{s} C \mathrm{~K}$-turn sequence migrates similarly to the five-adenine bulge species. Introduction of an $\mathrm{A} 67 \mathrm{C}$ mutation ( $\mathrm{Kt}^{\prime}$ variant) completely abolishes the K-turn structure, as previously observed for the Kt-7 variant (Goody et al. 2004). (C) Gel mobility shift assay of lysine aptamer as a function of the K-turn binding L7Ae protein. The aptamer was incubated in the presence of increasing concentrations of L7Ae, and the complexes analyzed by nondenaturing polyacrylamide gel electrophoresis. The aptamer was incubated in the absence (-) and in the presence of $0.8 \mathrm{nM}, 2 \mathrm{nM}, 5 \mathrm{nM}, 6.7 \mathrm{nM}, 10 \mathrm{nM}, 12.5$ $\mathrm{nM}, 16 \mathrm{nM}, 50 \mathrm{nM}$, and $100 \mathrm{nM}$ L7Ae. The free (F) and L7Ae-complexed aptamer (C) are indicated on the right. $(D)$ Graphical representation of the K-turn motif obtained from 32 lysine aptamer sequences. The logo has been arranged to match the secondary structure of the K-turn motif. A proportional representation for each residues is shown. Watson-Crick and purine base pairs are shown by vertical lines and circles, respectively. A star indicates the location of A67. Nucleotide positions are indicated below each representation.

Hagerman 1995). This value is very close to the observed subtended angle in crystal structures $\left(\sim 60^{\circ}\right)$ (Klein et al. 2001) and is consistent with the lysC K-turn motif adopting a structure very similar to a conventional K-turn motif. The effect of sequence changes in the G•A mismatches on the structure of the K-turn has been previously studied whereby the replacement of A67 by a cytosine highly perturbs the formation of the helical bend (Goody et al.
2004). Introducing a similar mutation in the context of the lysC K-turn $\left(\mathrm{Kt}^{\prime}\right.$ variant) clearly affected the migration pattern (Fig. 4B). The loss of the retarded migration is consistent with the inability of the mutated K-turn motif to adopt a highly kinked structure, as found in the Kt-7 motif (Goody et al. 2004). Thus, we conclude that a $\mathrm{K}$-turn motif is present in the $l_{s} \mathrm{C}$ riboswitch aptamer and that its folding properties are very similar to a conventional K-turn motif.

Despite variations in their sequences, K-turn structures found in rRNA all possess a similar three-dimensional structure where the average backbone RMSD is $1.7 \AA$ (Klein et al. 2001). Most of these K-turn sequences make significant interactions with ribosomal proteins of unrelated structures (Ban et al. 2000; Klein et al. 2001). To further characterize the $y_{s} C \mathrm{~K}$-turn motif, we studied its protein binding properties by using the L7Ae protein, which has previously been shown to bind the Kt-7 K-turn motif (Turner et al. 2005). We examined the binding of L7Ae to the complete riboswitch aptamer domain using gel electrophoretic retardation analysis (Fig. 4C). For this purpose we prepared a radioactively ${ }^{32} \mathrm{P}$-labeled $l_{s} \mathrm{C}$ aptamer molecule by in vitro transcription and incubated it with increasing concentrations of L7Ae. Our analysis by electrophoresis shows that two species are apparent and correspond to the free and to the L7Ae-aptamer complex. The radioactive bands were quantified and analyzed, and the data fitted very well to a simple model (see Materials and Methods) that assumes the noncooperative binding of L7Ae protein, giving a dissociation constant $\left(K_{d}\right)$ of $8.7 \pm 2.5$ $\mathrm{nM}$. This value is in good agreement with recent studies performed on the box $\mathrm{C} / \mathrm{D}$ snoRNA and the Kt-7 kinkturn motif, for which $K_{d}$ values near the low nanomolar range were found (Kuhn et al. 2002; Turner et al. 2005). The formation of the complex was also found to be specific, given that the $\mathrm{A} 67 \mathrm{C}$ mutation completely abolishes the formation of a complex with L7Ae (data not shown).

We used the WebLogo application (Crooks et al. 2004) to generate a graphical representation of the K-turn motif found in various L box aptamers obtained through the 
Rfam database (Griffiths-Jones et al. 2003). Among the 98 available sequences, several of them did not exhibit a recognizable K-turn motif, leading us to establish specific criteria that are found in most K-turn sequences. Specifically, flanking Watson-Crick base pairs, two tandem G•A pairs, and a stretch of three unpaired nucleotides (NNN) were used as selection criteria. Moreover, to avoid redundancy between variants, sequences that displayed more than $95 \%$ of homology over the entire aptamer sequence were included only once, thus yielding a total of 29 selected sequences. Finally, three additional sequences matching our selection criteria were found in the literature (Grundy et al. 2003), bringing the total number of sequences to 32. Using these sequences, a graphical representation of the K-turn motif was generated, which was arranged to match the known secondary structure consensus (Fig. 4D). From this analysis, we find that the identity of flanking Watson-Crick base pairs (base-pairs 64-87 and 69-79) is not conserved as long as base pairing is preserved. However, tandem $\mathrm{G} \bullet \mathrm{A}$ pairs (pairs 66-85 and 67-84) are conserved to a high degree, which is expected given their important role in the formation of the K-turn architecture (Moore et al. 2004). The most represented 3-nt single-stranded sequence corresponds to GAU, which is different from the sequence of the $B$. subtilis lys $C$ K-turn motif, but similar to the established K-turn consensus motif (Fig. 4D). However, according to this representation, K-turn motifs can be adopted from several other sequences that do not necessarily match the K-turn consensus. Taken together, our results indicate that K-turn sequences found in lysine aptamers may differ from the originally proposed K-turn motif and thus suggest that the K-turn element can be adopted by a diverse array of RNA sequences.

Next, we studied the formation of the loop-loop interaction using the RNase T1 endonuclease that is specific to single-stranded guanines. Using the RNase T1 assay, we have previously shown with the adenine riboswitch aptamer that a magnesium-dependent loop-loop interaction can form in absence of ligand (Lemay et al. 2006). We expected that the presence of magnesium ions would induce the formation of the loop-loop interaction and, upon its formation, that guanines located in the P2 loop (positions 72, 75 , and 76 ) would be protected from RNase T1 digestion.

In the context of the natural sequence (WT), RNase T1 cleavage is observed in the absence of magnesium ions at expected positions within the P2 loop region (Fig. 5A, G72, G75, and G76). In the presence of $10 \mathrm{mM}$ magnesium ions, strong protections are observed for all three positions, indicating the adoption of the loop-loop interaction. However, in the context of the $\mathrm{Kt}^{\prime}$ variant, which prevents the adoption of the K-turn structure, the magnesium-dependent protections are no longer observed, indicating the inability of the loop-loop interaction to form when the K-turn motif is not properly folded (Fig. 5A).

The functional importance of the K-turn motif was assessed by using a riboswitch variant carrying the $\mathrm{Kt}^{\prime}$ mutation using single-round transcription assays (Fig. 5B). We observe that the presence of the $\mathrm{Kt}^{\prime}$ mutation significantly disrupts the lysine-induced riboswitch regulation control, as shown by lower transcription termination efficiencies obtained in the absence and in the presence of lysine ( $\sim 13 \%$ and $\sim 31 \%$, respectively). This result is very similar to those obtained for the P2 and P3 riboswitch variants (Fig. 3), suggesting that the formation of the Kturn motif is important for the formation of the P2-P3 loop-loop interaction. Thus, as previously found for ribosomal (Klein et al. 2001) and small noncoding RNAs
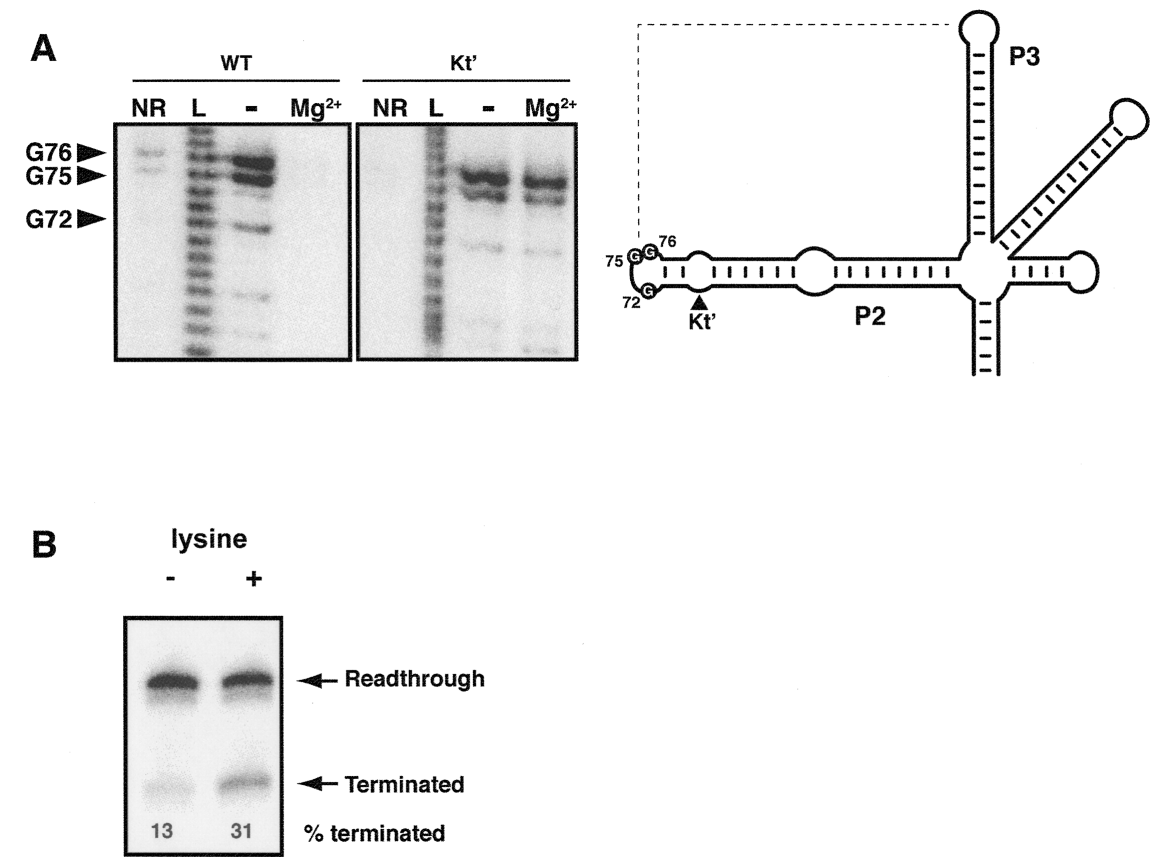

FIGURE 5. The kink-turn motif is important for loop-loop formation and transcription control. (A) Partial digestions of end-labeled wild-type and $\mathrm{Kt}^{\prime}$ variant aptamers by RNase T1 show that G72, G75, and G76 present in the P2 helical domain are protected from cleavage by the addition of magnesium for the wild-type molecule (left panel). However, no protection is observed when the $\mathrm{Kt}^{\prime}$ mutant is introduced in the aptamer (right panel). Lane NR contains unreacted RNA, while lane L contains RNA subjected to partial alkaline digestion. Positions of strong cleavage are indicated on the left. A schematic is shown on the right representing the three observed guanines and the loop-loop interaction. (B) Single-round transcriptions of the $\mathrm{Kt}^{\prime}$ mutant performed in the absence (-) and in the presence (+) of $5 \mathrm{mM}$ lysine. Readthrough and terminated products were separated by gel electrophoresis and are indicated on the right. The percentage of terminated product is indicated below the gel for each reaction. 
(Dennis and Omer 2005), K-turns also mediate important RNA tertiary structure interactions that are relevant for the biological function of riboswitches.

\section{lon-induced folding of the lysine aptamer domain}

Our single-round transcription data indicate that adoption of the loop-loop interaction, via the correct formation of the K-turn structure, is very important for the lysine riboswitch regulation. Since in-line probing has shown a reorganization of the folding of the core domain upon ligand binding (Sudarsan et al. 2003b), we speculated that formation of this tertiary interaction should be important for the folding of the lysine riboswitch core domain. We took advantage of the nonconserved nature of the core position 194 to introduce the fluorescent local reporter $2 \mathrm{AP}$ to make a spectroscopic study of conformational changes induced by magnesium ion binding. Fluorescence of $2 \mathrm{AP}$ is strongly quenched by the stacking of adjacent nucleobases, so changes in the intensity of fluorescence are indicative of changes in the local environment of the fluorophore (Ward et al. 1969; Xu et al. 1994; Stivers 1998; Jean and Hall 2001; Lafontaine et al. 2002b). 2AP fluorescence emission spectra were recorded in the presence of $90 \mathrm{mM}$ Tris-borate and $100 \mathrm{mM} \mathrm{KCl}$, and upon excitation of $2 \mathrm{AP}$, a relatively low fluorescence was detected, indicating that $2 \mathrm{AP}$ is not highly exposed to the solvent. However, upon addition of magnesium ions, an increase of the fluorescence intensity is observed, indicating that the $2 \mathrm{AP}$ local structure is altered, most probably resulting from the exposition of $2 \mathrm{AP}$ to the solvent (Fig. 6, inset). Fluorescence changes calculated for each magnesium ion concentration allow us to estimate apparent magnesium-binding parameters assuming a simple two-state transition model (see Materials and Methods). Good fits were obtained with this model, giving an apparent affinity for magnesium ions $\left[\mathrm{Mg}^{2+}\right]_{1 / 2}$ of 1.68 $\mathrm{mM}$ and a Hill coefficient $n=1.6 \pm 0.1$, suggesting a cooperative character for the transition of the 2AP fluorescence change (Table 1).

Formation of the loop-loop interaction was also studied using 2AP fluorescence. Aptamer variants were made in which either the P2 or the P3 loop region was exchanged for its counterpart and the resulting constructs were monitored using 2AP fluorescence (Fig. 6). Upon magnesium ion titration, it is immediately apparent that the folding of the aptamer domain is severely impaired, giving $\left[\mathrm{Mg}^{2+}\right]_{1 / 2}$ values of
$23.6 \mathrm{mM}$ and $38.1 \mathrm{mM}$ for the $\mathrm{P} 2$ and $\mathrm{P} 3$ variants, respectively (Table 1 ). Hill coefficient values were found to decrease slightly $(n \sim 1)$, but were not considered as an indicator of perturbed folding given the small magnitude change. We also tested the $\mathrm{P} 2+\mathrm{P} 3$ variant, and values of $\left[\mathrm{Mg}^{2+}\right]_{1 / 2}$ of $1.54 \mathrm{mM}$ and $n=1.4 \pm 0.1$ were obtained, which is very close to values obtained for the natural sequence (Table 1). In addition, given that the correct folding of the K-turn motif is required for loop-loop formation (Fig. 5A), we examined the effect of the disruption of the K-turn structure on the core folding. Upon introduction of the $\mathrm{Kt}^{\prime}$ mutation, the folding of the core is found to be perturbed, albeit to a lower extent compared to loop-loop variants, with values of $\left[\mathrm{Mg}^{2+}\right]_{1 / 2}=9.7 \mathrm{mM}$ and $n=1.1 \pm 0.1$. Taken together, our 2AP fluorescence results suggest that a structural reorganization is occurring in the core region of the lysine aptamer, and that this reorganization requires the formation of the kink-turn-dependent loop-loop interaction.

\section{DISCUSSION}

The study of riboswitches is of particular interest because RNA-ligand interactions are potentially very important in the elaboration of novel drug targets that could disrupt the expression of essential bacterial genes. Some examples clearly show that compounds competing with natural ligands such as lysine (Blount et al. 2007) and thiamine

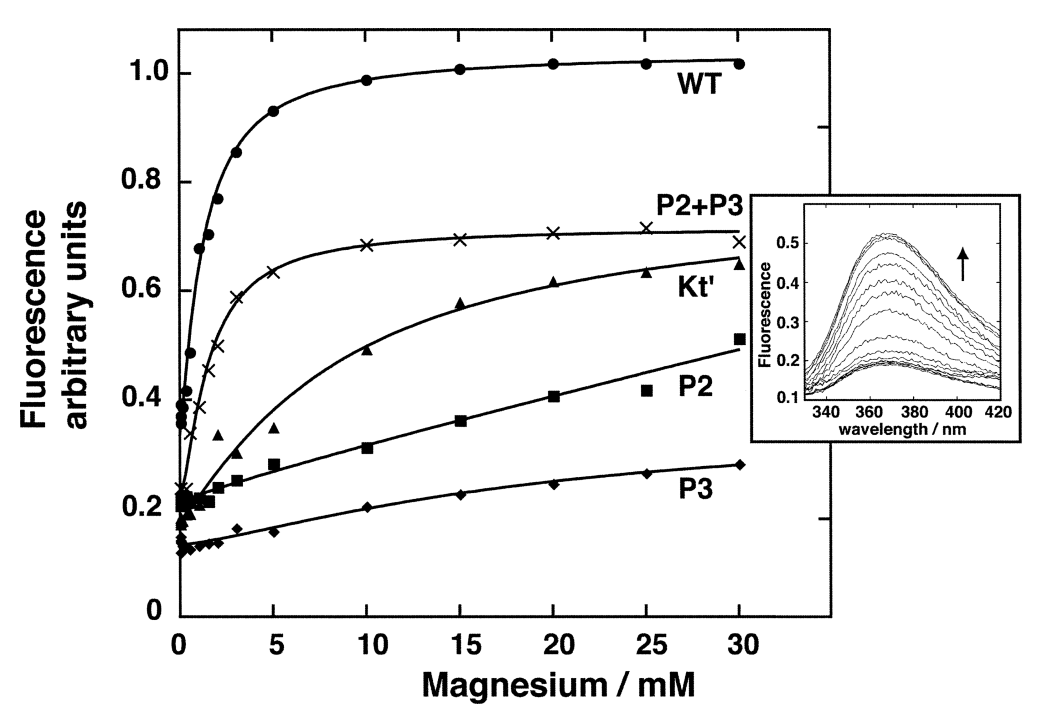

FIGURE 6. Formation of the loop-loop interaction is important for the reorganization of the aptamer core region. The insert shows fluorescence emission spectra $(\lambda e x=300 \mathrm{~nm})$ from 330 $\mathrm{nm}$ to $420 \mathrm{~nm}$ for each magnesium ion concentration. An increase of fluorescence is observed when the fluorescent lysine aptamer is incubated by the addition of magnesium ions. The normalized 2AP fluorescence intensity is plotted as a function of magnesium ions for the natural sequence (WT), the loop-loop-deficient variants P2 (squares) and P3 (diamonds), the doubly substituted aptamer P2 + P3 (crosses) and the K-turn-compromised variant (triangles). The experimental data were fitted (line) by regression to a simple two-state model where the binding of metal ions to the aptamer induces a structural change. 
TABLE 1. Magnesium ion titrations on 2AP-lysine aptamers

\begin{tabular}{lcc}
\hline Variant & $\begin{array}{c}{\left[\mathrm{Mg}^{2+}\right]_{1 / 2}} \\
(\mathrm{mM})\end{array}$ & $\begin{array}{c}\text { Hill coefficient } \\
(n)\end{array}$ \\
\hline $\mathrm{WT}$ & 1.68 & $1.6 \pm 0.1$ \\
$\mathrm{P}^{\mathrm{a}}$ & 23.6 & $1.1 \pm 0.3$ \\
$\mathrm{P3}^{\mathrm{b}}$ & 38.1 & $0.98 \pm 0.23$ \\
$\mathrm{P}^{2}+\mathrm{P}^{\mathrm{c}}$ & 1.54 & $1.4 \pm 0.1$ \\
$\mathrm{Kt}^{\prime \mathrm{d}}$ & 9.70 & $1.1 \pm 0.1$ \\
\hline
\end{tabular}

Half of apparent concentrations for the magnesium ion-induced process $\left(\left[\mathrm{Mg}^{2+}\right]_{1 / 2}\right)$ were measured under standard conditions. Asymptotic standard deviations on the fits indicate that errors in $\left[\mathrm{Mg}^{2+}\right]_{1 / 2}$ are generally less than $10 \%$ of values.

aNucleotides G72-G76 replaced with their Watson-Crick complement.

${ }^{\text {b}}$ Nucleotides C126-C130 replaced with their Watson-Crick complement.

${ }^{\mathrm{C}}$ Nucleotides G72-G76 relocated to positions 126-130, and nucleotides C126-C130 relocated to positions 72-76.

${ }^{\mathrm{d}}$ Nucleotide $\mathrm{A} 67$ replaced with a cytosine.

pyrophosphate (Sudarsan et al. 2005) alter the expression of essential genes and affect the viability of pathogenic bacteria. The lysine riboswitch has been previously shown to regulate the expression of genes involved in the lysine biosynthesis pathway or transport (Grundy et al. 2003; Rodionov et al. 2003; Sudarsan et al. 2003b). Previous works also showed that lysine induces premature termination of transcription of the B. subtilis lys $C$ gene by a riboswitch regulation mechanism. In this study, we performed a structural characterization of the lysine riboswitch aptamer domain and identified a novel tertiary interaction that is essential for the riboswitch activity.

While the existence of a loop-loop interaction in the lysine aptamer was previously proposed (Grundy et al. 2003; Rodionov et al. 2003), no direct experimental evidence was provided to unambiguously confirm its presence and its functional importance. Our single-round transcription data clearly show that the $y_{s} C$ lysine riboswitch relies on the formation of a loop-loop interaction to efficiently regulate transcription in presence of lysine (Fig. 3). Interestingly, loop-loop-deficient mutants (P2 and P3) still retain a certain capacity to respond to lysine during transcription. These results suggest that although riboswitch regulation is affected by loop-loop disruption, transcription regulation still occurs in a lysine-dependent manner, indicating that lysine can bind to the aptamer domain. Accordingly, in-line probing results of the lysine aptamer have shown that the core region of the aptamer is reorganized upon ligand binding; the lysine binding site is thus very likely to reside within the core region of the aptamer domain, and mutations performed peripherally of the aptamer are not likely to directly alter the ligand binding site (Sudarsan et al. 2003b). However, when the G39C mutation is introduced in the core of the aptamer, the riboswitch is unable to perform transcription regulation in the presence of lysine (Fig. 3), suggesting that G39 could be directly involved in the formation of the lysine binding site. This is supported by in-line probing results that have shown that the region J1/2, and therefore G39, is rearranged upon ligand binding (Sudarsan et al. 2003b). Thus, together with in-line probing data, our results suggest that the loop-loop interaction is required for the proper folding of the aptamer domain, but not for ligand binding.

Our 2AP fluorescence data show that the loop-loop formation occurs in the absence of ligand and influences the folding of the core (Fig. 6). The detailed analysis of the magnesium-induced folding process of the $y_{s} C$ riboswitch has revealed that the folding of the core domain is dependent on the correct formation of the loop-loop interaction, and that disruption of the loop-loop interaction leads to a marked decrease in the ability of the core to fold correctly. Because 2AP fluorescence experiments are performed in the absence of lysine, it suggests that the loop-loop interaction participates in the folding of the core in absence of ligand. This rearrangement could potentially be very important for the organization of the core region prior to ligand binding. Similarly, folding effects of a loop-loop interaction have also previously been characterized in the hammerhead ribozyme, where it was found that the magnesium ion concentration required for effective ribozyme cleavage was decreased (Khvorova et al. 2003; Penedo et al. 2004; Martick and Scott 2006). This indicates that these peripheral folding elements (i.e., loop-loop interaction) may be important as auxiliary folding enhancers and that, given their high representation in riboswitch secondary structures, may have important in vivo implications as found for the hammerhead ribozyme (Khvorova et al. 2003). In the present case, it is very likely that riboswitches bearing compromised loop-loop structures exhibit reduced transcription termination because embedded mutant aptamers are only partially folded and are thus precluded to perform efficient ligand binding under the conditions used for transcription assay.

The presence of an unconventional kink-turn structure is observed in the P2 helical domain of the aptamer (Fig. 1). Our native gel electrophoresis together with single-round transcription data indicate that the $y_{s} \mathrm{C} \mathrm{K}$-turn element introduces a sharp kink in an RNA helix very similar to an archetypal molecule (Klein et al. 2001; Goody et al. 2004), and that its correct folding is required for efficient riboswitch regulation (Figs. 4, 5B). Because it is located proximally to the $\mathrm{P} 2$ stem-loop, which is involved in the formation of the loop-loop interaction, it is very likely that correct folding of the K-turn is of primary importance for the formation of the loop-loop structure. Indeed, RNase $\mathrm{T} 1$ probing and $2 \mathrm{AP}$ fluorescence assays indicate that disruption of the K-turn inhibits formation of the looploop interaction and the magnesium-induced reorganization of the core domain of the aptamer (Figs. 5A, 6). Because the $l_{y s} C$ kink-turn does not fit the K-turn consensus sequence, the fact that it has similar folding 
properties compared to an archetypal motif suggests that K-turns are more widespread than previously envisioned (Klein et al. 2001), as described recently (Dennis and Omer 2005). This is supported by a recent study in which it was observed that K-turn motifs exhibiting characteristics similar to the $y_{s} C$ variant are also found numerous times in ribosomal K-turns (Lescoute et al. 2005). Furthermore, additional K-turns located in box $\mathrm{C} / \mathrm{D}$ and H/ACA of snoRNP are essential for methylation and pseudouridylation, where protein binding to the K-turn stabilizes the RNA kinked structure during the formation of the RNP complex (Henras et al. 2004; Dennis and Omer 2005; Turner et al. 2005).

Additional examples of kink-turn-containing RNA molecules can be found in alternative biological contexts. For instance, the crystal structure of the the SAM-responding riboswitch (Epshtein et al. 2003; McDaniel et al. 2003; Winkler et al. 2003) contains a kink-turn motif that is most likely important for the formation of a long-range pseudoknot structure (Montange and Batey 2006), both of which are important for the SAM riboswitch regulation (Winkler et al. 2001; McDaniel et al. 2005). In addition, in the $23 \mathrm{~S}$ ribosomal RNA, the Kt-7 kink-turn is located in the 5-6-7 junction (Ban et al. 2000; Klein et al. 2001). Interestingly, the 5-6-7 junction also exhibits a loop-loop interaction between two of its stem-loops, an arrangement very similar to what is found in the lys $C$ aptamer. However, in the case of the ribosomal junction, the crystal structure shows that ribosomal proteins L24 and L29 interact with Kt-7, suggesting that their presence could be important for the correct folding of the K-turn motif and, consequently, for the loop-loop structure (Ban et al. 2000). Thus, because $\mathrm{K}$-turn motifs serve as protein anchoring points in the building of complex architectures, the lys $C \mathrm{~K}$-turn could also be involved in protein interactions, as observed with L7Ae in our native gel assays (Fig. 4C). Although the in vivo relevance of this result needs to be experimentally addressed, it suggests that, even if such RNA elements can work in vitro without any protein factor, the in vivo mechanisms of some K-turn-containing riboswitches may be different by employing additional factors.

\section{MATERIALS AND METHODS}

\section{Synthesis of RNA molecules}

RNA molecules were transcribed from a PCR DNA template using T7 RNA polymerase (Milligan et al. 1987). All transcribed RNA species begin with a $5^{\prime}$-GCG sequence to minimize the $5^{\prime}$ heterogeneity of the RNA population (Pleiss et al. 1998). RNA molecules containing 2AP were purchased from Dharmacon, and deprotected and purified as described previously (Wilson and Lilley 2002). The internally labeled 2AP aptamer was assembled from oligonucleotides with the following sequences (all written $5^{\prime}$ to $3^{\prime}$ ): $5^{\prime}$-strand: GCGGUGAAGAUAGAGGUGCGAACUU
CAAGAGUAUGCCUUUGGAGAAAGAUGGAUUCUGUGAAAA AGGCUGAAAGGGGAGCGUCGCCGAAGCAAAUAAAACCCC AUCGGUAUUAUUUGCUGGCCGUGCAUUGAAUAAAUGUA AGGCUGUCAAGAAGCAUC; 3'-strand: 5'-PO4-AUUGCUUC UUGGAG(2AP)GCUAUCUUCACC. P2 and P3 variant sequences in the $5^{\prime}$-strand shown underlined represent the regions that were changed for their Watson-Crick counterpart for the study of the loop-loop interaction. Purified $5^{\prime}$ and $3^{\prime}$ RNA strands were annealed by heating a mixture (molar ratio $1.1: 1$ ) to $65^{\circ} \mathrm{C}$ in $10 \mathrm{mM}$ HEPES ( $\mathrm{pH} 7.5$ ), $50 \mathrm{mM} \mathrm{NaCl}$, and $10 \mathrm{mM} \mathrm{MgCl}_{2}$, and slowly cooled to $37^{\circ} \mathrm{C}$. T4 RNA ligase (New England BioLabs) was then added to the reaction, and samples were incubated at $37^{\circ} \mathrm{C}$ for $3 \mathrm{~h}$. Full-length ligated RNA molecules were purified by denaturing polyacrylamide gel electrophoresis, electroeluted, and dissolved in water.

The electrophoretic retardation of K-turn and oligoadenine bulged species was performed using 120 base-paired RNA duplexes. The RNA strand containing the 3-nt bulge of the duplex containing the lys $C \mathrm{~K}$-turn motif has the following sequence: GCGACACACGGACAAGCAAUGUGUGACGUAAUAUGGAGG GCGGACAAGCAAUGUGUGUUCUGUGAAAAAUGUACUGU UCAACUUGACAGUCCUCGCAUGUACUGUUCAACUUAAGA CCCACGCUUC, where the K-turn motif is underlined. The sequences of the A67C mutation and oligoadenine bulged species are derived from this sequence.

\section{In vitro transcription assays}

DNA templates for in vitro transcriptions were obtained by PCR with a combination of oligonucleotides corresponding to the B. subtilis glyQS promoter fused to the B. subtilis lysine riboswitch and a 95-nt sequence downstream from the expression platform. PCR products were cleaned with the Qiagen QIAquick gel extraction kit. The promoter region ends by an adenine and is fused to the $\mathrm{C} 17$ position of the riboswitch sequence, allowing the transcription to be initiated by the $\mathrm{ApC}$ dinucleotide. In the terminated species, RNAP stops at position 269. The readthrough species allows the RNAP to stop $95 \mathrm{nt}$ downstream from that position (i.e., $49 \mathrm{nt}$ after the AUG).

Reactions were initiated with $300 \mathrm{fmol}$ of DNA template in a buffer containing $150 \mu \mathrm{M}$ ApC, $2.5 \mu \mathrm{M}$ rATP and rGTP, $0.75 \mu \mathrm{M}$ rUTP, $2 \mu \mathrm{Ci}\left[\alpha^{-}{ }^{32} \mathrm{P}\right]-\mathrm{UTP}, 50 \mathrm{mM}$ Tris- $\mathrm{HCl}\left(\mathrm{pH} 8.0\right.$ at $\left.23^{\circ} \mathrm{C}\right)$, $20 \mathrm{mM} \mathrm{MgCl}_{2}, 0.1 \mathrm{mM}$ EDTA, $1 \mathrm{mM}$ DTT, 10\% glycerol, $0.25 \mathrm{U}$ E. coli RNAP (Epicentre), and L-lysine when required. This initiation mixture was incubated $15 \mathrm{~min}$ at $37^{\circ} \mathrm{C}$. Reactions were completed by the addition of each rNTP to a final concentration of $65 \mu \mathrm{M}$ and $0.45 \mathrm{mg} / \mathrm{mL}$ heparin to avoid reinitiation of transcription. Reactions were incubated at $37^{\circ} \mathrm{C}$ for an additional $15 \mathrm{~min}$ and stopped with an equal volume of formamide. Transcription products were analyzed using a 5\% denaturing PAGE and visualized on a PhosphorImager screen. The lysineinduced transcription termination can be described by the equation

$$
\alpha=\mathrm{T}_{\mathrm{I}}+\mathrm{T}_{\mathrm{M}} \cdot\left([\mathrm{ly} \sin \mathrm{e}] /\left(\mathrm{T}_{1 / 2}+[\text { ly } \sin \mathrm{e}]\right),\right.
$$

where $\alpha$ is the percentage terminated, $T_{I}$ and $T_{M}$ are the initial and maximal changes in transcription termination, and $T_{1 / 2}$ is the lysine concentration required to obtain half of the change. The 
equation assumes a simple 1:1 stoichiometry between the aptamer and lysine, as expected from in-line probing results (Sudarsan et al. 2003b). The reported errors are the standard uncertainties of the data from the best-fit theoretical curves. The standard uncertainty of the measurement is thus assumed to be approximated by the standard deviation of the points from the fitted curve (Flannery et al. 1992; Rist and Marino 2001).

\section{Fluorescence spectroscopy}

Fluorescence spectroscopy was performed on a Quanta Master fluorometer. All data were collected at $10^{\circ} \mathrm{C}$ in $90 \mathrm{mM}$ Tris-borate ( $\mathrm{pH} 8.3$ ) and $100 \mathrm{mM} \mathrm{KCl}$. Excitation for 2-aminopurine fluorescence was done at $300 \mathrm{~nm}$ to obtain a good separation between the Raman peak and 2AP fluorescence signal. Spectra were corrected for background, and intensities were determined by integrating data collected over the range $330-420 \mathrm{~nm}$.

Relative 2AP fluorescence was determined by monitoring the fluorescent emission of a fixed concentration of internally labeled 2AP lysine aptamer $(100 \mathrm{nM})$ and titrating the concentration of magnesium ions. Fluorescence data were fitted to a simple twostate model that assumes an all-or-none conformational transition induced by the binding of magnesium ions, with a Hill coefficient $n$ and an apparent association constant $K_{\mathrm{A}}$. The proportion of folded aptamer $(\alpha)$ is given by

$$
\alpha=K_{\mathrm{A}} \cdot\left[\mathrm{Mg}^{2+}\right]^{n} /\left(1+K_{\mathrm{A}} \cdot\left[\mathrm{Mg}^{2+}\right]^{n}\right) .
$$

As the parameters $K_{\mathrm{A}}$ and $n$ covary, we present the $\left[\mathrm{Mg}^{2+}\right]_{1 / 2}=(1 /$ $\left.K_{\mathrm{A}}\right)^{1 / n}$, which gives a robust estimate of the affinity for magnesium ions (Lafontaine et al. 2001, 2002a; Lemay et al. 2006).

\section{Gel electrophoresis under nondenaturing conditions}

Radioactively $\left[5^{\prime}-{ }^{32} \mathrm{P}\right]$-labeled RNA (final concentration $<1 \mathrm{nM}$ ) in $90 \mathrm{mM}$ Tris and $89 \mathrm{mM}$ boric acid ( $\mathrm{pH} \mathrm{8.5)} \mathrm{(TB} \mathrm{buffer)} \mathrm{and}$ $10 \mathrm{mM} \mathrm{MgCl}_{2}$ was electrophoresed in $10 \%$ acrylamide:bisacrylamide (29:1) gels in $\mathrm{TB}$ with $10 \mathrm{mM} \mathrm{MgCl}_{2}$ at $4^{\circ} \mathrm{C}$ at $150 \mathrm{~V}$ for $48 \mathrm{~h}$. The running buffer was circulated during electrophoresis. Gels were exposed to PhosphorImager screens.

\section{Gel electrophoresis under nondenaturing conditions in the presence of L7Ae}

RNA samples were prepared in $90 \mathrm{mM}$ Tris-borate $(\mathrm{pH} 8.3)$, $1 \mathrm{mM}$ EDTA $(1 \times \mathrm{TBE}), 25 \mathrm{mM} \mathrm{NaCl}$, and $5 \%$ glycerol. The concentration of L7Ae is indicated in the text. Mixtures were incubated on ice for $1 \mathrm{~h}$ before electrophoresis on $6.6 \%$ acrylamide:bisacrylamide (29:1) gels in $1 \times$ TBE with $25 \mathrm{mM} \mathrm{NaCl}$ at $4^{\circ} \mathrm{C}$ at $250 \mathrm{~V}$ for $5 \mathrm{~h}$. The running buffer was circulated during electrophoresis. Gels were exposed to PhosphorImager screens. The formation of L7Ae-aptamer complex was analyzed using a simple noncovalent binding model:

$$
\alpha=[\text { aptamer }] /\left(K_{\text {Dapp }}+[\text { aptamer }]\right),
$$

where $\alpha$ is the fraction bound and $K_{\text {Dapp }}$ is the apparent dissociation constant. The equation assumes a simple 1:1 stoichiometry between the aptamer and L7Ae, as is expected from the crystal structure (Moore et al. 2004).

\section{Partial RNase T1 cleavage}

$\left[5^{\prime}-{ }^{32} \mathrm{P}\right]$ RNA was incubated in $50 \mathrm{mM}$ Tris- $\mathrm{HCl}(\mathrm{pH} 8.3), 100$ $\mathrm{mM} \mathrm{KCl}$ in the absence or presence of $10 \mathrm{mM} \mathrm{MgCl}_{2}$ for $5 \mathrm{~min}$ at $37^{\circ} \mathrm{C}$. RNase $\mathrm{T} 1(0.2 \mathrm{U})$ was then added and allowed to react for $2 \mathrm{~min}$ at $37^{\circ} \mathrm{C}$. Reactions were stopped by the addition of a volume of $95 \%$ formamide. Products were separated on denaturing polyacrylamide gels, which were dried and exposed to a PhosphorImager screen.

\section{ACKNOWLEDGMENTS}

We thank members of the Lafontaine laboratory and Drs. Carlos Penedo and Alain Lavigueur for helpful discussions. We also thank D.M.J. Lilley for the generous gift of the L7Ae protein. This work was supported by the National Sciences and Engineering Research Council of Canada (NSERC). D.A.L. is a ChercheurBoursier Junior I of the Fonds de la Recherche en Santé du Québec.

Received March 14, 2007; accepted May 3, 2007.

\section{REFERENCES}

Ban, N., Nissen, P., Hansen, J., Moore, P.B., and Steitz, T.A. 2000. The complete atomic structure of the large ribosomal subunit at $2.4 \AA$ resolution. Science 289: 905-920.

Barrick, J.E., Corbino, K.A., Winkler, W.C., Nahvi, A., Mandal, M., Collins, J., Lee, M., Roth, A., Sudarsan, N., Jona, I., et al. 2004. New RNA motifs suggest an expanded scope for riboswitches in bacterial genetic control. Proc. Natl. Acad. Sci. 101: 6421-6426.

Bhattacharyya, A. and Lilley, D.M. 1989. The contrasting structures of mismatched DNA sequences containing looped-out bases (bulges) and multiple mismatches (bubbles). Nucleic Acids Res. 17: 6821-6840.

Bhattacharyya, A., Murchie, A.I., and Lilley, D.M. 1990. RNA bulges and the helical periodicity of double-stranded RNA. Nature 343: 484-487.

Blount, K.F., Wang, J.X., Lim, J., Sudarsan, N., and Breaker, R.R. 2007. Antibacterial lysine analogs that target lysine riboswitches. Nat. Chem. Biol. 3: 44-49.

Breaker, R.R. 2006. Riboswitches and the RNA world. In The RNA world, 3rd ed. (eds. R.F. Gesteland et al.), pp 89-108. Cold Spring Harbor Laboratory Press, Cold Spring Harbor, New York.

Crooks, G.E., Hon, G., Chandonia, J.M., and Brenner, S.E. 2004. WebLogo: A sequence logo generator. Genome Res. 14: 1188-1190.

Dennis, P.P. and Omer, A. 2005. Small noncoding RNAs in Archaea. Curr. Opin. Microbiol. 8: 685-694.

Diekmann, S. and Wang, J.C. 1985. On the sequence determinants and flexibility of the kinetoplast DNA fragment with abnormal gel electrophoretic mobilities. J. Mol. Biol. 186: 1-11.

Epshtein, V., Mironov, A.S., and Nudler, E. 2003. The riboswitchmediated control of sulfur metabolism in bacteria. Proc. Natl. Acad. Sci. 100: 5052-5056.

Flannery, B.P., Teukolsky, S.A., and Vetterling, W.T. 1992. Numerical recipes in Fortran, 2nd ed., Cambridge University Press, Cambridge, UK.

Gohlke, C., Murchie, A.I., Lilley, D.M., and Clegg, R.M. 1994. Kinking of DNA and RNA helices by bulged nucleotides observed by fluorescence resonance energy transfer. Proc. Natl. Acad. Sci. 91: $11660-11664$.

Goody, T.A., Melcher, S.E., Norman, D.G., and Lilley, D.M. 2004. The kink-turn motif in RNA is dimorphic and metal ion-dependent. RNA 10: 254-264.

Griffiths-Jones, S., Bateman, A., Marshall, M., Khanna, A., and Eddy, S.R. 2003. Rfam: An RNA family database. Nucleic Acids Res. 31: 439-441. 
Grundy, F.J. and Henkin, T.M. 2004. Regulation of gene expression by effectors that bind to RNA. Curr. Opin. Microbiol. 7: 126-131.

Grundy, F.J., Lehman, S.C., and Henkin, T.M. 2003. The L box regulon: Lysine sensing by leader RNAs of bacterial lysine biosynthesis genes. Proc. Natl. Acad. Sci. 100: 12057-12062.

Henras, A.K., Dez, C., and Henry, Y. 2004. RNA structure and function in C/D and H/ACA s(no)RNPs. Curr. Opin. Struct. Biol. 14: 335-343.

Hsieh, C.H. and Griffith, J.D. 1989. Deletions of bases in one strand of duplex DNA, in contrast to single-base mismatches, produce highly kinked molecules: Possible relevance to the folding of single-stranded nucleic acids. Proc. Natl. Acad. Sci. 86: 4833 4837.

Hutton, C.A., Southwood, T.J., and Turner, J.J. 2003. Inhibitors of lysine biosynthesis as antibacterial agents. Mini Rev. Med. Chem. 3: 115-127.

Jean, J.M. and Hall, K.B. 2001. 2-Aminopurine fluorescence quenching and lifetimes: Role of base stacking. Proc. Natl. Acad. Sci. 98: $37-41$.

Khvorova, A., Lescoute, A., Westhof, E., and Jayasena, S.D. 2003. Sequence elements outside the hammerhead ribozyme catalytic core enable intracellular activity. Nat. Struct. Biol. 10: 708-712.

Klein, D.J., Schmeing, T.M., Moore, P.B., and Steitz, T.A. 2001. The kink-turn: A new RNA secondary structure motif. EMBO J. 20: 4214-4221.

Kochhar, S. and Paulus, H. 1996. Lysine-induced premature transcription termination in the lysC operon of Bacillus subtilis. Microbiol. 142: 1635-1639.

Kubodera, T., Watanabe, M., Yoshiuchi, K., Yamashita, N., Nishimura, A., Nakai, S., Gomi, K., and Hanamoto, H. 2003. Thiamine-regulated gene expression of Aspergillus oryzae thiA requires splicing of the intron containing a riboswitch-like domain in the 5'-UTR. FEBS Lett. 555: 516-520.

Kuhn, J.F., Tran, E.J., and Maxwell, E.S. 2002. Archaeal ribosomal protein L7 is a functional homolog of the eukaryotic $15.5 \mathrm{kD} /$ Snu13p snoRNP core protein. Nucleic Acids Res. 30: 931-941.

Lafontaine, D.A., Norman, D.G., and Lilley, D.M. 2001. Structure, folding and activity of the VS ribozyme: Importance of the 2-3-6 helical junction. EMBO J. 20: 1415-1424.

Lafontaine, D.A., Norman, D.G., and Lilley, D.M. 2002a. The global structure of the VS ribozyme. EMBO J. 21: 2461-2471.

Lafontaine, D.A., Wilson, T.J., Zhao, Z.Y., and Lilley, D.M. 2002b. Functional group requirements in the probable active site of the VS ribozyme. J. Mol. Biol. 323: 23-34.

Lai, E.C. 2003. RNA sensors and riboswitches: Self-regulating messages. Curr. Biol. 13: R285-R291.

Lemay, J.F. and Lafontaine, D.A. 2007. Core requirements of the adenine riboswitch aptamer for ligand binding. RNA 13: 339-350.

Lemay, J.F., Penedo, J.C., Tremblay, R., Lilley, D.M., and Lafontaine, D.A. 2006. Folding of the adenine riboswitch. Chem. Biol. 13: 857-868.

Lescoute, A., Leontis, N.B., Massire, C., and Westhof, E. 2005. Recurrent structural RNA motifs, isostericity matrices and sequence alignments. Nucleic Acids Res. 33: 2395-2409.

Liao, H.H. and Hseu, T.H. 1998. Analysis of the regulatory region of the lysC gene of Escherichia coli. FEMS Microbiol. Lett. 168: 31-36.

Lilley, D.M. 1995. Kinking of DNA and RNA by base bulges. Proc. Natl. Acad. Sci. 92: 7140-7142.

Lilley, D.M.J., Clegg, R.M., Diekmann, S., Seeman, N.C., von Kitzing, E., and Hagerman, P. 1996. Nomenclature Committee of the International Union of Biochemistry: A nomenclature of junctions and branchpoints in nucleic acids. Recommendations 1994. J. Mol. Biol. 255: 554-555.

Lu, Y., Shevtchenko, T.N., and Paulus, H. 1992. Fine-structure mapping of cis-acting control sites in the lysC operon of Bacillus subtilis. FEMS Microbiol. Lett. 71: 23-27.

Luebke, K.J. and Tinoco Jr., I. 1996. Sequence effects on RNA bulgeinduced helix bending and a conserved five-nucleotide bulge from the group I introns. Biochemistry 35: 11677-11684.
Mader, U., Homuth, G., Scharf, C., Buttner, K., Bode, R., and Hecker, M. 2002. Transcriptome and proteome analysis of Bacillus subtilis gene expression modulated by amino acid availability. J. Bacteriol. 184: 4288-4295.

Mandal, M. and Breaker, R.R. 2004. Gene regulation by riboswitches. Nat. Rev. Mol. Cell Biol. 5: 451-463.

Mandal, M., Lee, M., Barrick, J.E., Weinberg, Z., Emilsson, G.M., Ruzzo, W.L., and Breaker, R.R. 2004. A glycine-dependent riboswitch that uses cooperative binding to control gene expression. Science 306: 275-279.

Marini, J.C., Levene, S.D., Crothers, D.M., and Englund, P.T. 1982. Bent helical structure in kinetoplast DNA. Proc. Natl. Acad. Sci. 79: 7664-7668.

Martick, M. and Scott, W.G. 2006. Tertiary contacts distant from the active site prime a ribozyme for catalysis. Cell 126: 309-320.

McDaniel, B.A., Grundy, F.J., Artsimovitch, I., and Henkin, T.M. 2003. Transcription termination control of the S box system: Direct measurement of S-adenosylmethionine by the leader RNA. Proc. Natl. Acad. Sci. 100: 3083-3088.

McDaniel, B.A., Grundy, F.J., and Henkin, T.M. 2005. A tertiary structural element in S box leader RNAs is required for Sadenosylmethionine-directed transcription termination. Mol. Microbiol. 57: 1008-1021.

Milligan, J.F., Groebe, D.R., Witherell, G.W., and Uhlenbeck, O.C. 1987. Oligoribonucleotide synthesis using T7 RNA polymerase and synthetic DNA templates. Nucleic Acids Res. 15: 8783-8798.

Montange, R.K. and Batey, R.T. 2006. Structure of the S-adenosylmethionine riboswitch regulatory mRNA element. Nature 441: $1172-1175$.

Moore, T., Zhang, Y., Fenley, M.O., and Li, H. 2004. Molecular basis of box C/D RNA-protein interactions; cocrystal structure of archaeal L7Ae and a box C/D RNA. Structure 12: 807-818.

Nudler, E. and Mironov, A.S. 2004. The riboswitch control of bacterial metabolism. Trends Biochem. Sci. 29: 11-17.

Patte, J.C. 1994. Biosynthesis of threonine and lysine. American Society for Microbiology, Washington, DC.

Patte, J.C., Akrim, M., and Mejean, V. 1998. The leader sequence of the Escherichia coli lysC gene is involved in the regulation of LysC synthesis. FEMS Microbiol. Lett. 169: 165-170.

Penedo, J.C., Wilson, T.J., Jayasena, S.D., Khvorova, A., and Lilley, D.M. 2004. Folding of the natural hammerhead ribozyme is enhanced by interaction of auxiliary elements. RNA 10: 880888.

Pleiss, J.A., Derrick, M.L., and Uhlenbeck, O.C. 1998. T7 RNA polymerase produces $5^{\prime}$ end heterogeneity during in vitro transcription from certain templates. RNA 4: 1313-1317.

Rist, M. and Marino, J. 2001. Association of an RNA kissing complex analyzed using 2-aminopurine fluorescence. Nucleic Acids Res. 29: 2401-2408.

Rodionov, D.A., Vitreschak, A.G., Mironov, A.A., and Gelfand, M.S. 2003. Regulation of lysine biosynthesis and transport genes in bacteria: Yet another RNA riboswitch? Nucleic Acids Res. 31: 6748-6757.

Rodionov, D.A., Vitreschak, A.G., Mironov, A.A., and Gelfand, M.S. 2004. Comparative genomics of the methionine metabolism in Gram-positive bacteria: A variety of regulatory systems. Nucleic Acids Res. 32: 3340-3353.

Schluenzen, F., Tocilj, A., Zarivach, R., Harms, J., Gluehmann, M., Janell, D., Bashan, A., Bartels, H., Agmon, I., Franceschi, F., et al. 2000. Structure of functionally activated small ribosomal subunit at 3.3 angstroms resolution. Cell 102: 615-623.

Stivers, J.T. 1998. 2-Aminopurine fluorescence studies of base stacking interactions at abasic sites in DNA: Metal-ion and base sequence effects. Nucleic Acids Res. 26: 3837-3844.

Sudarsan, N., Barrick, J.E., and Breaker, R.R. 2003a. Metabolitebinding RNA domains are present in the genes of eukaryotes. RNA 9: 644-647.

Sudarsan, N., Wickiser, J.K., Nakamura, S., Ebert, M.S., and Breaker, R.R. 2003b. An mRNA structure in bacteria that controls gene expression by binding lysine. Genes \& Dev. 17: 2688-2697. 
Sudarsan, N., Cohen-Chalamish, S., Nakamura, S., Emilsson, G.M., and Breaker, R.R. 2005. Thiamine pyrophosphate riboswitches are targets for the antimicrobial compound pyrithiamine. Chem. Biol. 12: $1325-1335$.

Sudarsan, N., Hammond, M.C., Block, K.F., Welz, R., Barrick, J.E., Roth, A., and Breaker, R.R. 2006. Tandem riboswitch architectures exhibit complex gene control functions. Science 314: 300304.

Tang, R.S. and Draper, D.E. 1990. Bulge loops used to measure the helical twist of RNA in solution. Biochemistry 29: 52325237.

Turner, B., Melcher, S.E., Wilson, T.J., Norman, D.G., and Lilley, D.M. 2005. Induced fit of RNA on binding the L7Ae protein to the kink-turn motif. RNA 11: 1192-1200.

Vold, B., Szulmajster, J., and Carbone, A. 1975. Regulation of dihydrodipicolinate synthase and aspartate kinase in Bacillus subtilis. J. Bacteriol. 121: 970-974.

Ward, D.C., Reich, E., and Stryer, L. 1969. Fluorescence studies of nucleotides and polynucleotides. I. Formycin, 2-aminopurine riboside, 2,6-diaminopurine riboside, and their derivatives. J. Biol. Chem. 244: 1228-1237.

Wilson, T.J. and Lilley, D.M. 2002. Metal ion binding and the folding of the hairpin ribozyme. RNA 8: 587-600.

Winkler, W.C. 2005. Riboswitches and the role of noncoding RNAs in bacterial metabolic control. Curr. Opin. Chem. Biol. 9: 594-602.

Winkler, W.C., Grundy, F.J., Murphy, B.A., and Henkin, T.M. 2001. The GA motif: An RNA element common to bacterial antitermination systems, rRNA, and eukaryotic RNAs. RNA 7: 1165-1172.

Winkler, W.C., Nahvi, A., Sudarsan, N., Barrick, J.E., and Breaker, R.R. 2003. An mRNA structure that controls gene expression by binding S-adenosylmethionine. Nat. Struct. Biol. 10: 701-707.

Xu, D., Evans, K.O., and Nordlund, T.M. 1994. Melting and premelting transitions of an oligomer measured by DNA base fluorescence and absorption. Biochemistry 33: 9592-9599.

Zacharias, M. and Hagerman, P.J. 1995. Bulge-induced bends in RNA: Quantification by transient electric birefringence. J. Mol. Biol. 247: 486-500. 

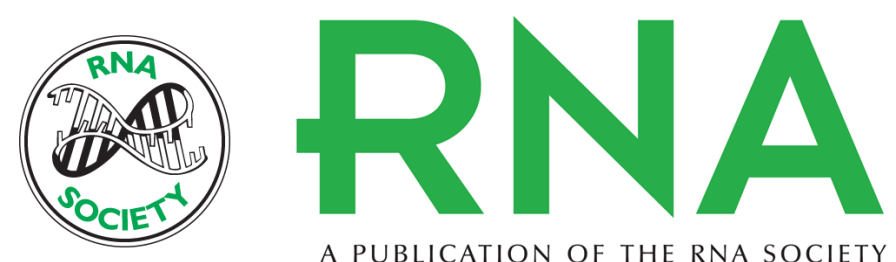

A PUBLICATION OF THE RNA SOCIETY

\section{A loop-loop interaction and a K-turn motif located in the lysine aptamer domain are important for the riboswitch gene regulation control}

Simon Blouin and Daniel A. Lafontaine

RNA 2007 13: 1256-1267 originally published online June 21, 2007

Access the most recent version at doi:10.1261/rna.560307

References This article cites 68 articles, 26 of which can be accessed free at:

http://rnajournal.cshlp.org/content/13/8/1256.full.html\#ref-list-1

\section{License}

Email Alerting Receive free email alerts when new articles cite this article - sign up in the box at the Service top right corner of the article or click here.

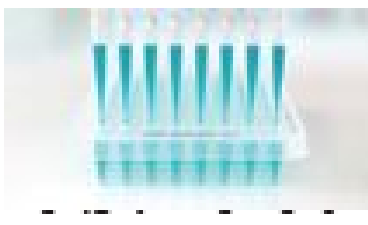

Providing Precise Solutions for your research.

To subscribe to $R N A$ go to:

http://rnajournal.cshlp.org/subscriptions 